\title{
Desensitisation of calcitonin gene-related peptide responsiveness but not adrenomedullin responsiveness in vascular smooth muscle cells
}

\author{
W M Drake, S R Lowe, A Mirtella, T J Bartlett and A J L Clark \\ Molecular Endocrinology Laboratory, Departments of Endocrinology and Chemical Endocrinology, St Bartholomew's Hospital, West Smithfield, \\ London EC1A 7BE, UK \\ (Requests for offprints should be addressed to W M Drake, Department of Endocrinology, St Bartholomew's Hospital, West Smithfield, London EC1A 7BE, UK)
}

\begin{abstract}
Adrenomedullin (ADM) and calcitonin gene-related peptide (CGRP) are distantly related peptides. Both act through $G$ protein-coupled receptors on vascular smooth muscle cells to increase intracellular cAMP concentrations, causing vasorelaxation. Recent evidence suggests that both peptides bind to a common heptahelical receptor, with specificity for each peptide being determined by a receptor activity modifying protein (RAMP). This hypothesis predicts that each peptide should desensitise the cellular response to subsequent stimulation by the other. We have studied the patterns of desensitisation of ADM/CGRP receptors in rat aortic vascular smooth muscle cells. Cells were incubated for $20 \mathrm{~min}$ in either serum free medium (SFM), alone (control) or in SFM containing vasoactive agonist (e.g. ADM $10^{-8} \mathrm{M}$, CGRP $10^{-7} \mathrm{M}$, angiotensin II $10^{-9} \mathrm{M}$ or isoproterenol $10^{-6} \mathrm{M}$ ). Cells were then washed and incubated for a further $20 \mathrm{~min}$ in SFM containing a second agonist and $1 \mathrm{mM}$ isobutyryl methyl xanthine. Cells were harvested and assayed for cAMP.
\end{abstract}

Pre-exposure of cells to CGRP, isoproterenol, angiotensin II or ADM, decreased cAMP generation in response to subsequent stimulation with CGRP by $84 \%( \pm 5), 66 \%$ $( \pm 18), 45 \%( \pm 5)$ and $60 \%( \pm 10)$ respectively (mean \pm s.D.). Pre-incubation of cells with $100 \mathrm{nM} \mathrm{H-89}$, a protein kinase A (PKA) inhibitor, abolished the desensitisation of CGRP by itself, implying that this desensitisation was mediated through PKA. In contrast, there was no attenuation of the cAMP response to stimulation with ADM by pre-exposure to ADM and all other agonists tested. Identical results were seen with or without PKA inhibition by $\mathrm{H}-89$. These results indicate that the ADM receptor does not desensitise over this time period in RAVSMCs, in contrast to the CGRP receptor, which is desensitised by pre-exposure to CGRP and other vasoactive agonists. These data also suggest that ADM and CGRP act through separate receptors in these cells.

Journal of Endocrinology (2000) 165, 133-138

\section{Introduction}

Adrenomedullin (ADM) and calcitonin gene-related peptide (CGRP) are distantly related, potent vasodilatory peptides, sharing structural similarity in the form of a conserved N-terminal disulphide loop. Both act on vascular smooth muscle cells (VSMC) to stimulate adenylate cyclase and hence increase intracellular cAMP levels, resulting in vasorelaxation (Nuki et al. 1993). Although much is known about the distribution of CGRP, $\mathrm{ADM}$ and their receptors in man and other mammals (Richards et al. 1996, Wimalawansa 1996), it remains unclear whether they act through a common receptor or separate receptors, and what the respective roles of these peptides are in health and disease.

A recent report (McLatchie et al. 1998) suggested that both peptides bind to the same seven transmembrane domain receptor (termed the calcitonin receptor-like receptor, CRLR), with receptor specificity being conferred by the presence of receptor activity modifying proteins (RAMPs). RAMPs are single transmembrane domain proteins that appear to be important in the $\mathrm{N}$-linked glycosylation of CRLR and in the binding of peptide ligands. According to the proposed model, coexpression of CRLR with RAMP1 in A293 cells results in a CGRP receptor, whereas when CRLR is expressed with RAMP2 in the same cells, ADM receptor pharmacology is acquired. Earlier studies with GTP $\gamma \mathrm{S}$ (Yamaguchi et al. 1988, Eguchi et al. 1994) indicated that the receptors for CGRP and ADM are G protein coupled receptors (GPCRs), stimulating adenylate cyclase through $\mathrm{G}_{\mathrm{s}}$. Most members of the GPCR 'superfamily' display the phenomenon of desensitisation (Tsuga et al. 1994, Barker et al. 1995, Freedman et al. 1995), in which the size of the intracellular signal generated by the agonist-occupied receptor is attenuated in response to repeated exposure of 
the receptor to the ligand. If $\mathrm{ADM}$ and CGRP act through a common receptor (the CRLR) then one would predict that they should 'cross-desensitise', such that pre-exposure to either peptide would attenuate the size of the intracellular signal generated by subsequent exposure to the other. We have previously shown, in the neuroblastoma SK-N-MC cell line, that the desensitisation patterns to each peptide are markedly different (Drake et al. 1999). In order to further these studies in a more physiological system, we studied, in vitro, the patterns of desensitisation of ADM and CGRP receptors in primary cultures of rat aortic vascular smooth muscle cells (RAVSMCs). This was achieved by measuring the quantities of cAMP produced by sequential stimulation of these cells with different combinations of vasoactive agonists.

\section{Materials and Methods}

\section{RAVSMCs}

Primary cultures of RAVSMCs were prepared according to the protocol described by Clapp \& Gurney (1991). The aorta was removed from a dead male Wistar rat, cut into strips, incubated in dissociation medium containing $0.16 \mathrm{mM} \mathrm{Ca}^{2+}$ and subsequently incubated overnight at $4{ }^{\circ} \mathrm{C}$ in $0.2 \mathrm{mg} / \mathrm{ml}$ papain. Following re-warming and dispersion, single cells were then isolated and grown in Dulbecco's modified eagle medium (Sigma, Poole, Dorset, UK) containing $10 \%$ fetal bovine serum, $100 \mathrm{mU} / \mathrm{ml}$ penicillin and $100 \mu \mathrm{g} / \mathrm{ml}$ streptomycin, in a humidified atmosphere of $95 \%$ air, $5 \% \mathrm{CO}_{2}$. Subcultured VSMCs (passages 4-13) were used.

\section{Experimental protocol}

Cells were grown to confluency in six well plates and, after washing in serum-free medium (SFM), were incubated at $37^{\circ} \mathrm{C}$ for $20 \mathrm{~min}$ in either SFM alone (control) or SFM containing agonists at the following concentrations: isoproterenol $10^{-6} \mathrm{M}$, CGRP $10^{-7} \mathrm{M}$, ADM $10^{-8} \mathrm{M}$, angiotensin II $10^{-9} \mathrm{M}$ (isoproterenol and angiotensin, Sigma, UK; CGRP and ADM, Peninsula Labs Europe, Merseyside, UK). The concentrations of CGRP and ADM used were based on dose-response curves for these peptides (data not shown). After the initial $20 \mathrm{~min}$ incubation, cells were washed in SFM and incubated for a second $20 \mathrm{~min}$ in SFM containing a second agonist. For the second incubation step isobutyryl methylxanthine (Sigma, UK) was added at a concentration of $1 \mathrm{mM}$ to inhibit phosphodiesterases. At the end of the second incubation period, cells were harvested, boiled for 5 min to inactivate phosphodiesterases, centrifuged at 10000 r.p.m. for $3 \mathrm{~min}$ to remove cell debris and the cAMP content of the supernatant assayed. Cyclic AMP production during the second ('collection') step was compared with production by cells that were incubated for $20 \mathrm{~min}$ in SFM alone and then with agonist for $20 \mathrm{~min}$, and which therefore underwent a single stimulation only.

Protein kinase A (PKA) inhibition was achieved by pre-incubating cells for $30 \mathrm{~min}$ at $37^{\circ} \mathrm{C}$ in SFM containing $100 \mathrm{nM} \quad \mathrm{N}$-[2-(p-bromocinnamylamino) ethyl]-5-isoquinolinesulphonamide (H-89, CalBiochem, Nottingham, UK). Cells were then incubated, as above, in SFM containing $100 \mathrm{nM} \mathrm{H}-89$ and agonist. Between incubations, cells were washed in SFM containing $100 \mathrm{nM}$ H-89.

Cyclic AMP assay

Cyclic AMP was measured by a competitive binding assay as described previously (Brown et al. 1971). Tritiated and non-tritiated cAMP were purchased from Amersham, Bucks, UK and Sigma, UK respectively.

\section{Statistical analysis}

Results are expressed as pmol/well confluent cells and represent the mean \pm S.D. of three separate, duplicated experiments, each assayed in duplicate for cAMP. Data were compared using Student's unpaired $t$-test.

\section{Results}

The concentrations of agonist used in subsequent desensitisation experiments were based on a calculated $\mathrm{EC}_{50}$ of $3.9 \times 10^{-9}$ and $6.6 \times 10^{-8}$ for ADM and CGRP respectively (data not shown). In Figs 1 and 2, cAMP production is presented as a percentage of that produced during a simultaneously run single incubation with agonist. Pre-exposure of cells to CGRP, isoproterenol, angiotensin II or ADM at the above concentrations attenuated the subsequent CGRP-stimulated generation of cAMP by $84 \%( \pm 5), 66 \%( \pm 18), 45 \%( \pm 5)$ and $60 \%$ $( \pm 10)$ respectively (Fig. 1A). Attenuation of cAMP production by pre-exposure of cells to CGRP, isoproterenol and ADM was completely abolished by inhibition of PKA with $100 \mathrm{nM} \mathrm{H-89}$ (Fig. 1A). Pre-exposure of cells to isoproterenol attenuated the subsequent isoproterenolstimulated generation of cAMP by $50 \%( \pm 12)$; mean ( \pm S.D.). This effect was unchanged by inhibition of PKA with H-89 (Fig. 1B). In contrast, pre-exposure of cells to CGRP, ADM and angiotensin II had no effect on subsequent $\mathrm{ADM}$-induced cAMP generation and was unaffected by pre-incubation with H-89 (Fig. 2). Identical results were seen during a single experiment using the same protocol with rat renal VSMCs prepared by the same technique. 


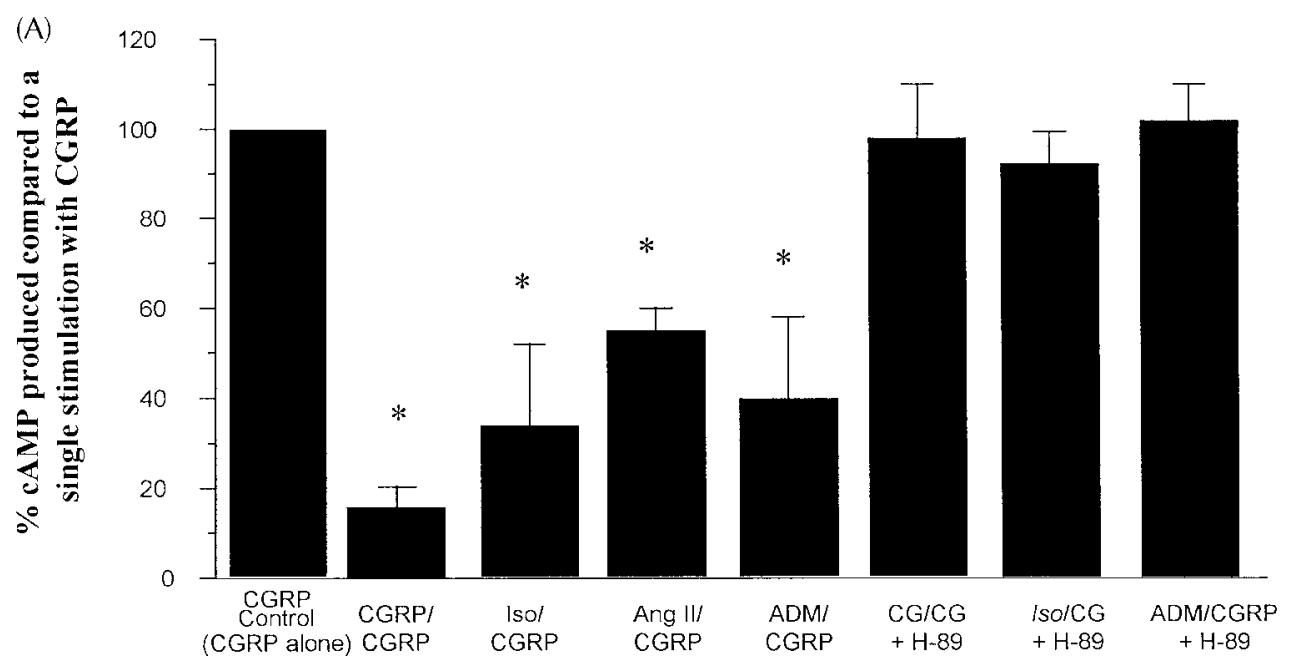

Sequence of agonists

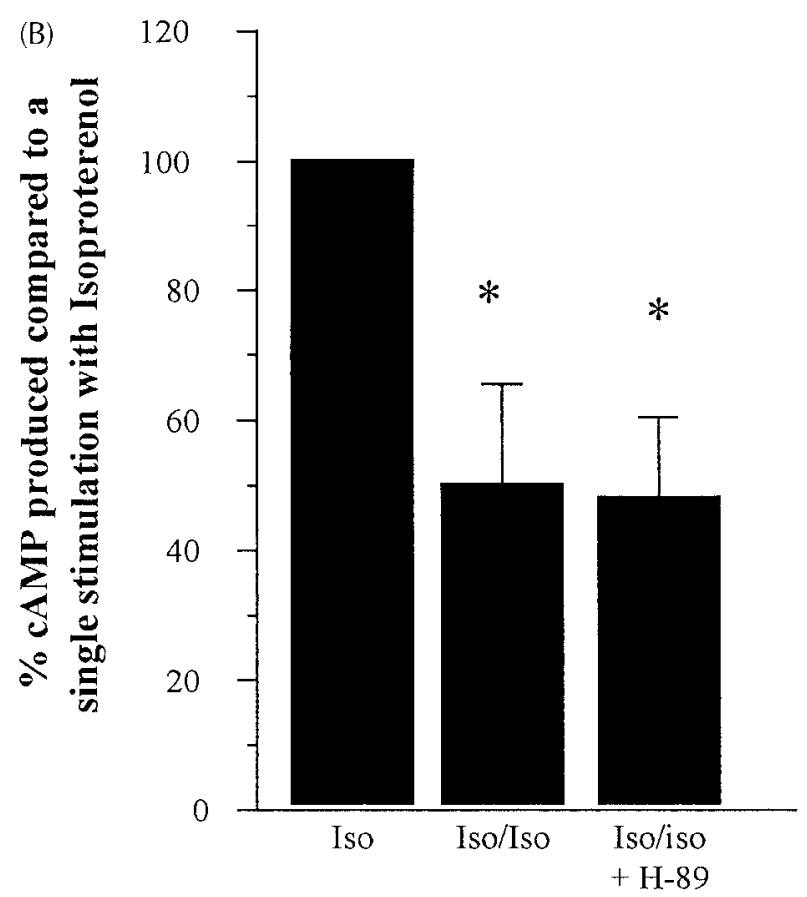

\section{Sequence of agonists}

Figure 1 (A) CGRP-mediated CAMP generation by RAVSCMs in response to sequential stimulation with vasoactive agonists. CAMP generated by a single stimulation with CGRP was $93 \pm 23 \mathrm{pmol} /$ well, ${ }^{*} P<0 \cdot 001$. (B) CAMP generation by RAVSMCs in response to stimulation with isoproterenol (iso) alone, iso/iso and iso/iso in the presence of $\mathrm{H}-89$. cAMP generated by a single stimulation with CGRP was $73 \pm 12 \mathrm{pmol} /$ well, ${ }^{\star} P<0 \cdot 001$.

\section{Discussion}

Since the discovery of CGRP in 1983 (Rosenfeld et al. 1983) and ADM in 1993 (Kitamura et al. 1993), much has been learnt about the distribution of these related peptide hormones and their receptors in various mammals (Richards et al. 1996, Wimalawansa 1996). The presence of ADM in human plasma, its synthesis and release by 


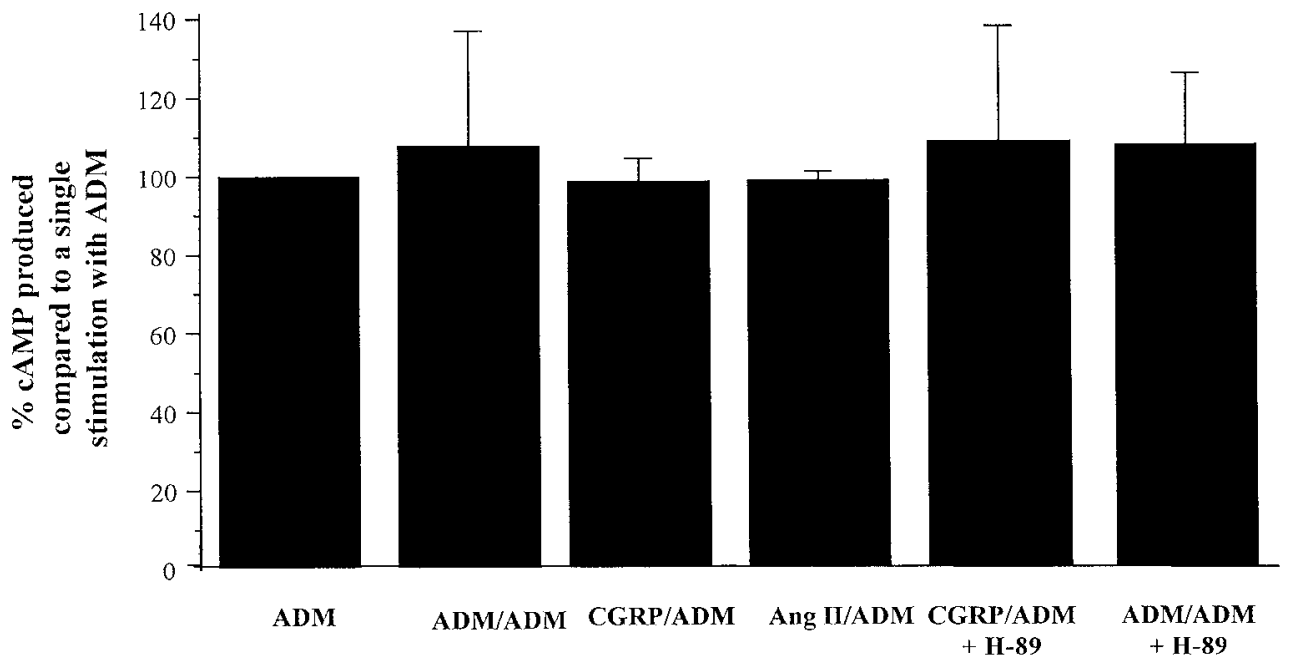

\section{Sequence of agonists}

Figure 2 ADM-mediated CAMP generation by RAVSMCs in response to sequential stimulation with vasoactive agonists. cAMP generated by a single stimulation with ADM was $153 \pm 21 \mathrm{pmol} / \mathrm{well}$.

endothelial cells and its elevation in conditions such as hypertension (Ishimitsu et al. 1994) point to a possible role in the control of vascular tone. Studies with GTP $\gamma \mathrm{S}$ (Yamaguchi et al. 1988, Eguchi et al. 1994) have shown that ADM and CGRP both act through GPCRs. Other GPCRs found on cells of the vascular system (such as $\beta$-adrenergic and angiotensin II receptors) exhibit the phenomenon of desensitisation, in which the amplitude of the intracellular signal generated by an agonist-occupied receptor decreases despite repeated exposure of the cells to agonist (Barker et al. 1995, Freedman et al. 1995). By analogy, we reasoned that the receptors that mediate the intracellular response to ADM and CGRP would exhibit desensitisation and that if these two peptides acted through a common receptor then pre-exposure of cells to one peptide would attenuate the size of the intracellular signal generated by subsequent exposure to the other. We have previously shown, in the human neuroblastoma SKN-MC cell line, that the desensitisation patterns of ADM and CGRP responsiveness are markedly different (Drake et al. 1999). Given the postulated role of these peptides in the control vascular tone, we have attempted to study the patterns of desensitisation in a more physiological system, using primary cultures of RAVSMCs. Using an identical protocol to the one described here, the ability of cells to generate cAMP in response to stimulation with ADM is not altered by a 20-min pre-exposure of cells to either ADM or CGRP. In contrast, the responsiveness of cells to CGRP diminished significantly when cells were pre-exposed to either peptide.

This study provides good evidence that ADM and CGRP act through separate receptors in RAVSMCs.
Generation of cAMP by stimulation with CGRP was reduced by pre-exposure of the cells to various vaso-active agonists. The desensitisation effect of pre-exposure to CGRP and ADM was completely abolished by H-89 at a concentration that selectively inhibits PKA without affecting protein kinase (PK)C activity (Chijiwa et al. 1990), indicating that this process was probably PKA mediated. In contrast, generation of cAMP by stimulation with ADM could not be attenuated by pre-exposure of the cells to CGRP, ADM or angiotensin II.

Alternative explanations for these data include the possibility that the CRLR/RAMP hypothesis is correct, and that RAMP2 interferes with the desensitisation process. A further possibility is that different RAMPs in association with CRLR, in addition to influencing ligand binding, lead to activation of different intracellular second messenger pathways which in turn result in different patterns of desensitisation. These alternative models seem less likely, but should be readily testable.

Desensitisation has been particularly well studied in $\beta$-adrenergic receptors ( $\beta A R)$, in which the responsiveness of cells to stimulation with catecholamines is, to some extent, determined by the phosphorylation state of critical amino acid residues in the third intracytoplasmic loop and the C-terminal tail of the receptor (Hausdorff et al. 1990). This, in turn, is controlled by two intracellular enzymes, $\beta$-adrenergic receptor kinase ( $\beta$ ARK/GRK 2 ) and PKA, both of which are stimulated following binding of ligand to the $\beta A R$. Homologous desensitisation phosphorylation of specific serine and threonine residues in the C-terminal tail of the receptor by GRKs leads to binding of a $\beta$-arrestin molecule. This inhibits further 
signal transduction by preventing interaction of the receptor with the linked $G$ protein. Heterologous desensitisation of the $\beta A R$ is mediated through activation of PKA which phosphorylates amino acid residues on the C-terminal tails and/or cytoplasmic loops of a variety of receptors. In the case of the $\beta A R$, desensitisation occurs via a combination of homologous and heterologous processes. We therefore hypothesised that the CGRP/ADM receptor would desensitise by more than one mechanism. However, it appears that desensitisation of CGRP receptor(s) in RAVSMCs in the model described is mediated entirely by activation of PKA, as selective inhibition of PKA during pre-exposure of cells to CGRP or ADM did not attenuate cAMP production during subsequent stimulation with CGRP. Homologous desensitisation is clearly intact in our experimental system, as shown by the fact that preexposure of cells to isoproterenol attenuates subsequent cAMP generation by the same agonist even when PKA is inhibited by $\mathrm{H}-89$.

The effect of pre-exposure to ADM and other agonists on subsequent ADM responsiveness of RAVSMCs has recently been reported (Iwasaki et al. 1998). In that study, ADM responsiveness was dramatically attenuated $2 \mathrm{~h}$ after pre-exposure to ADM, a situation that persisted for at least $24 \mathrm{~h}$. In a separate set of experiments by the same workers, pre-exposure of cells to isoproterenol and forskolin for $5 \mathrm{~h}$ did not alter subsequent ADM responsiveness. These findings do not necessarily conflict with our own. The time course over which ADM responsiveness was lost in their experiments is likely to have been due to receptor internalisation and sequestration rather than phosphorylation and desensitisation which, for $\beta A R$ at least, takes place over seconds or minutes after even the briefest encounter with ligand (Hausdorff et al. 1990). Binding studies using radiolabelled ADM, with or without preexposure to 'cold' peptide, would be informative in this regard.

The finding that ADM receptors in these cells appear to avoid rapid desensitisation raises interesting questions about their function in health and disease. ADM causes relaxation of rat cerebral arterioles (Nishimura \& Suzuki 1997) and has been shown to limit ischaemic brain injury following cerebral artery occlusion in rats (Dogan et al. 1997). The site of production of most ADM is endothelial cells, and it seems highly probable that ADM acts in a paracrine manner on vascular smooth muscle cells (VSMCs) to increase local blood flow around areas of ischaemic tissue, where the presence of a non-desensitising receptor would ensure that the vasodilatory signal would not be lost or attenuated. It is tempting to speculate that, in man, the lack of desensitisation of the ADM receptor that we have observed in RAVSMCs is a protective mechanism, limiting already ischaemic tissues from further insult.

In summary, we have shown evidence that ADM and CGRP act through separate receptors in RAVSMCs: findings that do not fit easily with the CRLR/RAMP hypothesis as presently stated. Furthermore, the ADM receptor does not show the desensitisation that is characteristic of almost all other G-protein coupled receptors thus far studied. Further work is required to elucidate the mechanisms by which ADM receptors avoid desensitisation and to clarify the physiological significance of these findings in health and disease.

\section{Acknowledgements}

W M D is supported by the Joint Research Board of St Bartholomew's Hospital, London, UK. S R L and A M are supported by the British Heart Foundation, UK. T J B is British Diabetic Association post-doctoral research fellow.

\section{References}

Barker S, Kapas S, Fluck RJ \& Clark AJL 1995 Effects of the selective protein kinase C inhibitor Ro31-7549 on human angiotensin II receptor desensitisation and intracellular calcium release. FEBS Letters $369263-266$.

Brown BL, Albano JD, Ekins RP, Sgherzi AM \& Tampion W 1971 A simple and sensitive saturation assay method for the measurement of adenosine $3^{\prime} 5^{\prime}$-cyclic monophosphate. Biochemical Journal 121 561-562.

Chijiwa T, Mishima A, Hagiwara M et al. 1990 Inhibition of forskolin-induced neurite outgrowth and protein phosphorylation by a newly synthesized selective inhibitor of cyclic AMP-dependent protein kinase, N-[2-(p-bromocinnamylamino) ethyl]-5isoquinoline-sulfonamide (H-89), of PC12D pheochromocytoma cells. Journal of Biological Chemistry 265 5267-5272.

Clapp LH \& Gurney AM 1991 Outward currents in rabbit pulmonary artery cells dissociated with a new technique. Experimental Physiology 76 677-693.

Drake WM, Ajayi A, Lowe SR, Mirtella A, Bartlett TJ \& Clark AJL 1999 Desensitisation of CGRP and adrenomedullin receptors in SK-N-MC cells: implications for the RAMP hypothesis. Endocrinology 140 533-537.

Dogan A, Suzuki Y, Koketsu N et al. 1997 Intravenous infusion of adrenomedullin and increase in regional cerebral blood flow and prevention of ischemic brain injury after middle cerebral artery occlusion in rats. Journal of Cerebral Blood Flow and Metabolism 17 19-25.

Eguchi S, Hirata Y, Iwasaki H et al. 1994 Structure-activity relationship of adrenomedullin, a novel vasodilatory peptide, in cultured rat vascular smooth muscle cells. Endocrinology 135 2454-2458.

Freedman NJ, Liggett SB, Drachman DE, Pei G, Caron MG \& Lefkowitz RJ 1995 Phosphorylation and desensitisation of the human $\beta$-adrenergic receptor. Journal of Biological Chemistry 270 17953-17961.

Hausdorff WP, Caron MG \& Lefkowitz RJ 1990 Turning off the signal: desensitisation of $\beta$-adrenergic function. FASEB Journal 4 2881-2889.

Ishimitsu T, Nishikimi T, Saito Y et al. 1994 Plasma levels of adrenomedullin, a newly identified peptide, in patients with hypertension and renal failure. Journal of Clinical Investigation 94 2158-2161.

Iwasaki H, Eguchi S, Shichirim M, Marumo F \& Hirata Y 1998 Down regulation of adenylate cyclase coupled to adrenomedullin receptor in vascular smooth muscle cells. European Journal of Pharmacology 352 131-134. 
Kitamura K, Kangawa K, Kawanoto et al. 1993 Adrenomedullin: a novel hypotensive peptide isolated from human pheochromocytoma. Biochemical and Biophysical Research Communications 192 553-560.

McLatchie LM, Fraser NJ, Main MJ et al. 1998 RAMPs regulate the transport and ligand specificity of the calcitonin-receptor-like receptor. Nature 393 333-339.

Nishimura Y \& Suzuki A 1997 Relaxant effects of vasodilator peptides on isolated basilar arteries from stroke-prone spontaneously hypertensive rats. Clinical and Experimental Pharmacology and Physiology 24 157-161.

Nuki C, Kawasaki H, Kitamura et al. 1993 Vasodilator effect of adrenomedullin and calcitonin gene-related peptide receptors in rat mesenteric vascular beds. Biochemical and Biophysical Research Communications 196 245-251.

Richards AM, Nicholls MG, Lewis L \& Lainchbury JG 1996 Adrenomedullin. Clinical Science 91 3-16.

Rosenfeld MG, Mermod JJ, Amara SG et al. 1983 Production of a novel neuropeptide encoded by the calcitonin gene via tissue specific RNA processing. Nature 304 129-135.
Tsuga H, Kameyama K, Haga T, Kurose H \& Nagao T 1994 Sequestration of muscarinic acetylcholine receptor $\mathrm{m} 2$ subtypes. Facilitation by G-protein coupled receptor kinase (GRK2) and attenuation by a dominant negative mutant of GRK2. Journal of Biological Chemistry 269 32522-32527.

Wimalawansa SJ 1996 Calcitonin gene-related peptide and its receptors: molecular genetics, physiology, pathophysiology and therapeutic potentials. Endocrine Reviews 17 533-585.

Yamaguchi A, Chiba T, Yamatani T et al. 1988 Calcitonin gene-related peptide stimulates adenylate cyclase activation via a guanine nucleotide-dependent process in rat liver plasma membranes. Endocrinology 123 2591-2596.

Received 20 May 1999

Revised manuscript received 13 August 1999

Final manuscript received 13 October 1999

Accepted 29 November 1999 